\title{
Hydrogen Annealing on the Structural, Optical and Magnetic Properties of Yb-Doped Zno Diluted Magnetic Semiconductor Thin Films
}

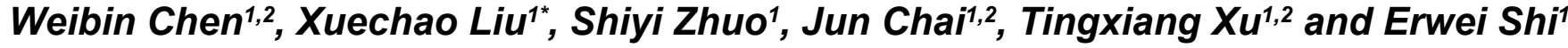 \\ ${ }^{1}$ Shanghai Institute of Ceramics, Chinese Academy of Sciences, People's Republic of China \\ ${ }^{2}$ Graduate School of the Chinese Academy of Sciences, People's Republic of China
}

\begin{abstract}
$\mathrm{Zn}_{0.985} \mathrm{Yb}_{0.015} \mathrm{O}$ thin films have been prepared by using inductively coupled plasma enhanced physical vapor deposition method. The as-deposited $\mathrm{Zn}_{0.985} \mathrm{Yb}_{0.015} \mathrm{O}$ thin films are annealed in hydrogen atmosphere at different temperatures from $500{ }^{\circ} \mathrm{C}$ to $700{ }^{\circ} \mathrm{C}$. The structural, optical and magnetic properties are characterized by using different measurement techniques. All the annealed $\mathrm{Zn}_{0.985} \mathrm{Yb}_{0.015} \mathrm{O}$ thin films show room-temperature ferromagnetism and the saturation magnetization exhibits a similar dependency on the annealing temperature. The photoluminescence spectra imply that oxygen vacancy defects obviously rise with the increase in annealing temperature. It is found that oxygen vacancies can act as bound magnetic polaron and play an important role in the ferromagnetic coupling in $\mathrm{Yb}$-doped $\mathrm{ZnO}$ thin films.
\end{abstract}

\section{Introduction}

Diluted magnetic semiconductor (DMS) is considered as a promising material for spintronic devices [1,2]. DMS can simultaneously take advantage of electronic charge and spin and operate with faster speed, less energy consumption and higher efficiency. Zinc oxide $(\mathrm{ZnO})$ is regarded as a suitable DMS material when doping with transition metals or rare earth metals. ZnO-based DMS can exhibit room-temperature ferromagnetism, which has been theoretically predicted by T. Ditel [3]. However, the origin of spin coupling still remains under debate. Many factors such as electrons [4], holes [5], intrinsic defects and stress [6] can play important roles in the magnetic properties. Coey, et al. [7] proposed a theoretical model of bound magnetic polaron (BMP) in connection with semi-insulating materials where ferromagnetic exchange is mediated by defects and form BMPs. Up to present, many experiments have proven that intrinsic point defects, such as oxygen vacancies $\left(\mathrm{V}_{\mathrm{O}}\right)[8,9]$, zinc vacancies $\left(\mathrm{V}_{\mathrm{Zn}}\right)[10,11]$, zinc interstitial $\left(\mathrm{Zn}_{\mathrm{i}}\right)$ [12], and oxygen interstitial $\left(\mathrm{O}_{\mathrm{i}}\right)$ [13] are indeed related to ferromagnetism in DMS materials. But how the defects function in DMS materials remains a complex puzzle.

Ytterbium $(\mathrm{Yb})$ can be used as the dopant for $\mathrm{ZnO}$ based DMS due to its matchable ion radius with $\mathrm{Zn}^{2+}$. Previous research [14] claimed that the ferromagnetism in $\mathrm{Yb}$-doped $\mathrm{ZnO}$ was induced by the coexistence of oxygen vacancies and $\mathrm{Yb}$ point defects. In order to understand the role of oxygen vacancies in $\mathrm{Yb}$-doped $\mathrm{ZnO}$, we perform a series of annealing experiments at different temperatures since oxygen easily escapes from $\mathrm{ZnO}$ lattice in reducing atmosphere. In this paper, an in-depth study on the influence of annealing temperature on structural, optical and magnetic properties of $\mathrm{Yb}$-doped $\mathrm{ZnO}$ thin films is performed. The origin of room-temperature ferromagnetism in $\mathrm{Yb}$-doped $\mathrm{ZnO}$ thin films is discussed. We specially focus on the influence of oxygen vacancies on the ferromagnetism.

${ }^{*}$ Corresponding author: Xuechao Liu, Shanghai Institute of Ceramics, Chinese Academy of Sciences, Shanghai 201800, People's Republic of China, Tel: +86-2169987663, Fax: +86-2169987661, E-mail: xcliu@mail.sic.ac.cn

Received: April 13, 2018: Accepted: June 25, 2018: Published: June 27, 2018

Copyright: (c) 2018 Chen W, et al. This is an open-access article distributed under the terms of the Creative Commons Attribution License, which permits unrestricted use, distribution, and reproduction in any medium, provided the original author and source are credited. 

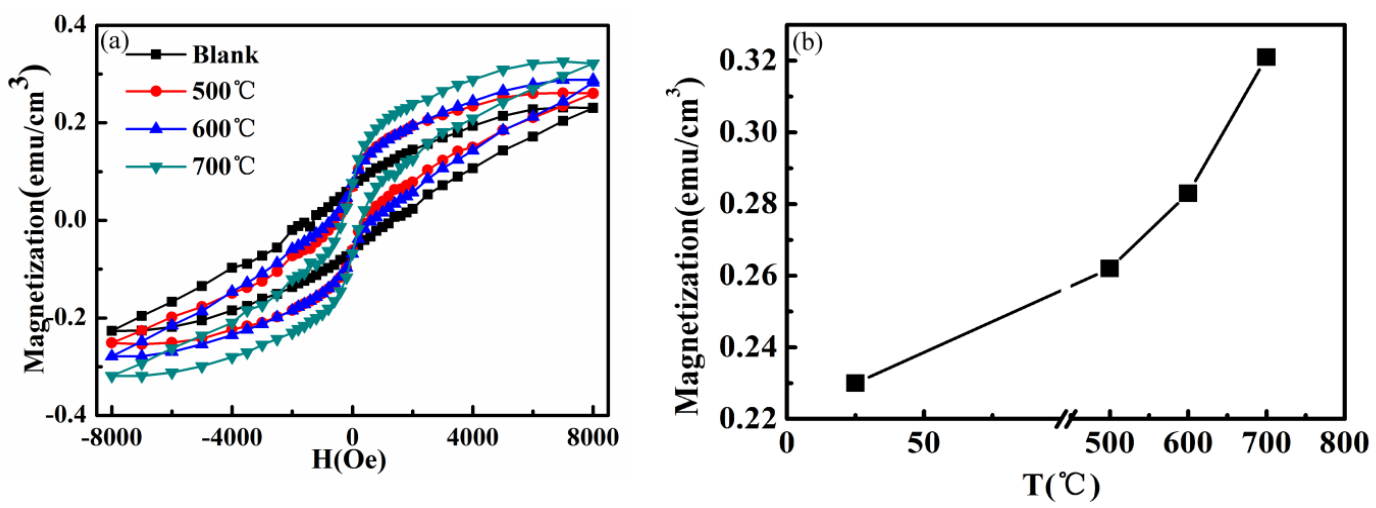

Figure 1: a) Magnetization versus magnetic field (M-H) curves for $\mathrm{Zn}_{0.985} \mathrm{Yb}_{0.015} \mathrm{O}$ thin films annealed at $500{ }^{\circ} \mathrm{C}, 600{ }^{\circ} \mathrm{C}$ and $700{ }^{\circ} \mathrm{C}$ in $\mathrm{H}_{2}$ atmosphere for $1 \mathrm{~h}$; b) The dependence of saturation magnetization on annealing temperature for $\mathrm{Zn}_{0.985} \mathrm{Yb}_{0.015} \mathrm{O}$ thin films.

\section{Experiment}

Yb-doped $\mathrm{ZnO}$ thin films $\left(\mathrm{Zn}_{0.985} \mathrm{Yb}_{0.015} \mathrm{O}\right)$ are deposited on sapphire substrates by using inductively coupled plasma enhanced physical vapor deposition method. The deposition temperature, sputtering power, and the argon partial pressure is $300{ }^{\circ} \mathrm{C}, 120 \mathrm{~W}$ and $1.2 \mathrm{~Pa}$, respectively. The thickness of $\mathrm{Zn}_{0.985} \mathrm{Yb}_{0.015} \mathrm{O}$ thin films is controlled at $400 \mathrm{~nm}$ by adjusting the deposition time. After the $\mathrm{Zn}_{0.985} \mathrm{Yb}_{0.015} \mathrm{O}$ thin films are prepared, they are loaded in the heating zone of a tube furnace for annealing treatment. The furnace is refilled with high purity $\mathrm{H}_{2}$ until achieving atmospheric pressure, followed by increasing the temperature to $500{ }^{\circ} \mathrm{C}, 600{ }^{\circ} \mathrm{C}$ and $700{ }^{\circ} \mathrm{C}$ at a rate of $10^{\circ} \mathrm{C} / \mathrm{min}$, then keep at the annealing temperature for 1 $\mathrm{h}$. The as-deposited $\mathrm{Zn}_{0.985} \mathrm{Yb}_{0.015} \mathrm{O}$ thin film is marked as blank in the following figures.

The magnetic properties of $\mathrm{Yb}$-doped $\mathrm{ZnO}$ thin films were measured by using a superconducting quantum interference device (SQUID, Quantum Design MPMS) magnetometer. The phase composition and crystal structure were characterized by using a X-ray diffractometer (XRD, Rigaku Ultima IV) with $\mathrm{Cu}$ Ka radiation $(\lambda$ $=1.5406 \AA$ ). The Raman and photoluminescence (PL) spectra were performed on a confocal Raman spectroscope (Renishaw, Invia Raman microscope) with $325 \mathrm{~nm}$ wavelength $\mathrm{He}-\mathrm{Cd}$ laser. The chemical bonding formation was analyzed by X-ray photoelectron spectroscopy (XPS) measurement (XPS, Thermo Scientific ESCALAB $250)$ with Al Ka X-ray (1486.6 eV).

\section{Results and Discussion}

\section{Magnetic properties}

Figure 1a shows the magnetization versus magnetic field $(\mathrm{M}-\mathrm{H})$ curves measured at room temperature for $\mathrm{Yb}$-doped $\mathrm{ZnO}$ thin films. The diamagnetic background signal of sapphire substrate has been subtracted. It can be seen that all the samples exhibit clear ferromagnetic hys-

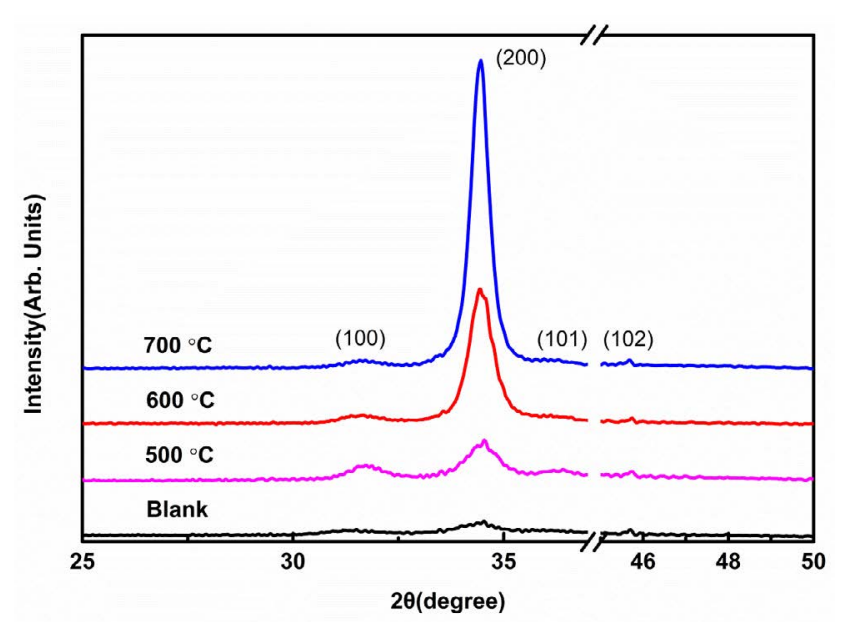

Figure 2: $X R D$ patterns of $\mathrm{Zn}_{0.985} \mathrm{Yb}_{0.015} \mathrm{O}$ thin films after an-

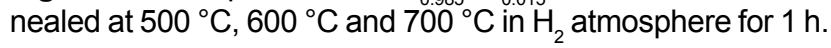

teresis loops. The saturation magnetization for different $\mathrm{Zn}_{0.985} \mathrm{Yb}_{0.015} \mathrm{O}$ thin films, as shown in Figure $1 \mathrm{~b}$, is 0.230 , $0.260,0.283$ and $0.321 \mathrm{emu} / \mathrm{cm}^{3}$, respectively. The ferromagnetism of $\mathrm{Yb}$-doped $\mathrm{ZnO}$ thin films exhibits an obvious enhancement after annealing in $\mathrm{H}_{2}$ atmosphere. That is to say, the higher annealing temperature, the stronger magnetization, meaning a correlation between the ferromagnetism and annealing temperature.

\section{Structural properties}

$\mathrm{XRD}$ are used to study the crystal structure of $\mathrm{Yb}$ doped $\mathrm{ZnO}$ thin films. Figure 2 shows the XRD patterns of $\mathrm{Zn}_{0.985} \mathrm{Yb}_{0.015} \mathrm{O}$ thin films after annealed at different temperatures. The comparison of peak positions with standard Joint Committee for powder diffraction standard files suggests that all the $\mathrm{Zn}_{0.985} \mathrm{Yb}_{0.015} \mathrm{O}$ thin films are polycrystalline. The XRD results reveal a single hexagonal wurtzite structure of $\mathrm{Zn}_{0.985} \mathrm{Yb}_{0.015} \mathrm{O}$ thin film without $\mathrm{Yb}$ cluster and $\mathrm{Yb}$-related oxides. With the increase in annealing temperature, the intensity of $\mathrm{ZnO}$ (002) diffraction peak slightly moves to higher level and the FWHM value of $\mathrm{ZnO}$ (002) become smaller, which 
Table 1: The distance (d) between the (002) lattice plane and the average grain size (D) of the films calculated from XRD pattern.

\begin{tabular}{|l|l|l|l|l|}
\hline Temperature & FWHM (deg.) & $\mathbf{2 \theta}$ (deg.) & d (nm) & D (nm) \\
\hline Blank & 0.920 & 34.354 & 0.5217 & 9.038 \\
\hline $500^{\circ} \mathrm{C}$ & 0.659 & 34.457 & 0.5202 & 12.621 \\
\hline $600{ }^{\circ} \mathrm{C}$ & 0.608 & 34.477 & 0.5199 & 13.681 \\
\hline $700^{\circ} \mathrm{C}$ & 0.487 & 34.477 & 0.5199 & 17.080 \\
\hline
\end{tabular}

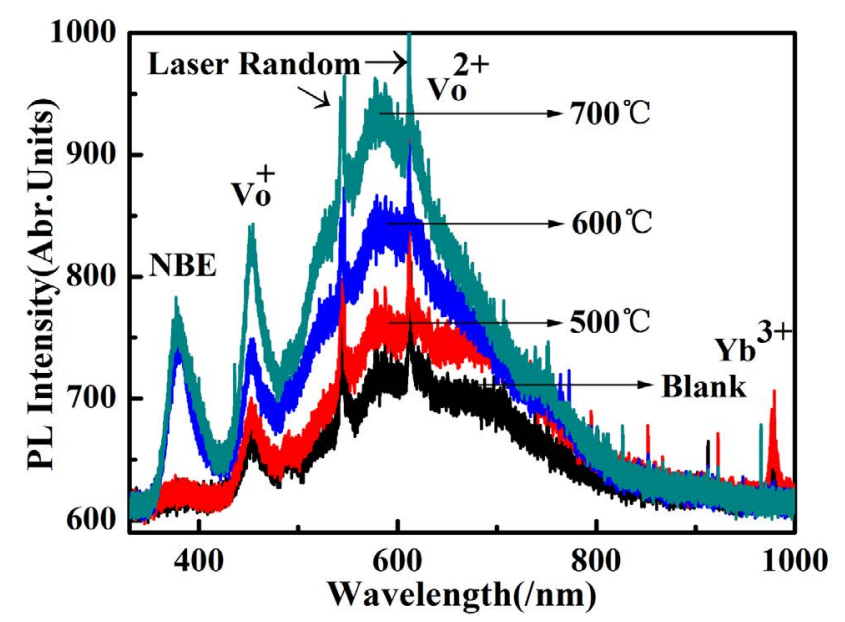

Figure 3: Room-temperature $\mathrm{PL}$ spectra of $\mathrm{Zn}_{0.985} \mathrm{Yb}_{0.015} \mathrm{O}$ thin films after annealed at $500{ }^{\circ} \mathrm{C}, 600{ }^{\circ} \mathrm{C}$ and $700{ }^{\circ} \mathrm{C}$ in $\mathrm{H}_{2}$ atmosphere for $1 \mathrm{~h}$.

jointly indicates that high annealing temperature can improve the crystallization quality and the orientation of crystalline grains converts to $\mathrm{ZnO}(002)$ on the $c$-sapphire substrate.

To further characterize the crystal quality, the average grain size in $\mathrm{Zn}_{0.985} \mathrm{Yb}_{0.015} \mathrm{O}$ thin films is calculated by Scherrer formula [15] and shown in Table 1.

$$
D=\frac{0.9 \lambda}{\beta \cos \theta}
$$

Wherein $\lambda, \beta$, and $\theta$ are the X-ray wavelength (1.5406 $\AA$ ), diffraction angle, and FWHM of $\mathrm{Zn}_{0.985} \mathrm{Yb}_{0.015} \mathrm{O}$ (002) peak. It can be seen that the grain size gradually rises with the increase in annealing temperature and reaches a maximum value when the annealing temperature is $700{ }^{\circ} \mathrm{C}$. Larger grain size means less proportion of grain boundary and better crystallization quality.

\section{Photoluminescence spectra}

Photoluminescence (PL) spectra can be used to detect defects in thin film materials. Figure 3 shows the room-temperature PL spectra of $\mathrm{Zn}_{0.985} \mathrm{Yb}_{0.015} \mathrm{O}$ thin films after annealed at different temperatures. It can be seen from Figure 3, four peaks located at $380 \mathrm{~nm}, 460 \mathrm{~nm}$, $580 \mathrm{~nm}$ and $980 \mathrm{~nm}$ are excited by $325 \mathrm{~nm}$ wavelength laser. The origin of these four PL peaks will be discussed in detail in the follow text. The ultraviolet emission at 380 $\mathrm{nm}$ is the characteristic of a near-band-edge (NBE) transition of wide-band-gap intrinsic $\mathrm{ZnO}$. With the increase

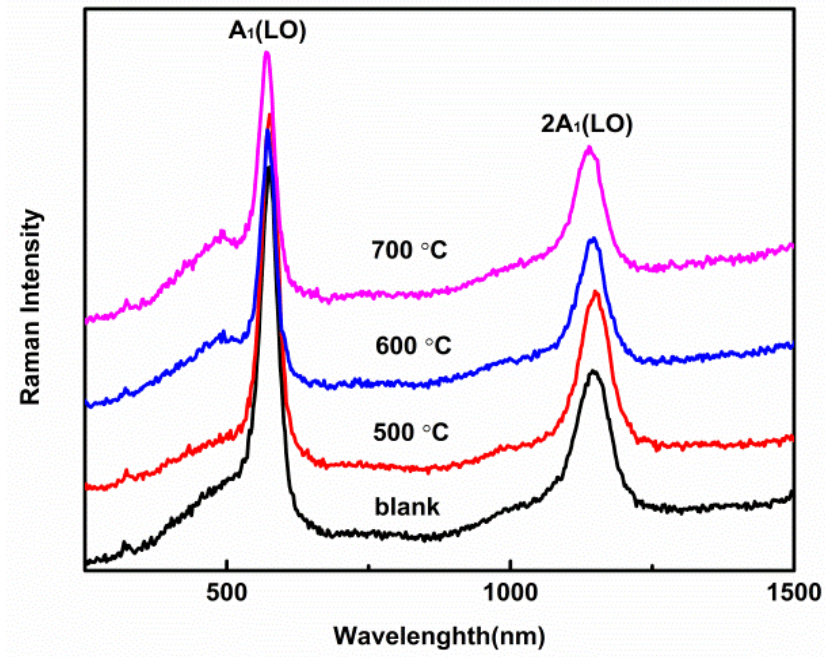

Figure 4: Room-temperature Raman spectra of $\mathrm{Zn}_{0.985} \mathrm{Yb}_{0.015} \mathrm{O}$ thin films after annealed at $500{ }^{\circ} \mathrm{C}, 600{ }^{\circ} \mathrm{C}$ and $700{ }^{\circ} \mathrm{C}$ in $\mathrm{H}_{2}$ atmosphere for $1 \mathrm{~h}$.

in annealing temperature, the intensity of NBE increases to higher level, meaning that elevating annealing temperature can make the crystal structure quality perfect with fewer non-irradiation recombination defects. This is consistent with XRD analysis. The explicit mechanism of blue PL emission centering at $460 \mathrm{~nm}$ is not clear so far. Most of the reports attributed the blue emission due to the presence of oxygen vacancies occurring between 420 and $480 \mathrm{~nm}$. Chen [16] synthesized $\mathrm{ZnO}$ quantum dots (QDs) with strong blue emission at $460 \mathrm{~nm}$ by gel-sol method. Moreover, Jana [17] prepared $\mathrm{ZnO}$ nanorods exhibiting blue emission at same wavelength. They both concluded that the blue emission is due to the transition from deep donor level by singly ionized oxygen vacancies $\left(\mathrm{V}_{\mathrm{o}}^{+}\right)$to the valence band. A broad defect-related visible emission centering at $580 \mathrm{~nm}$ is commonly attributed to the doubly charged oxygen vacancies $\mathrm{V}_{\mathrm{o}}^{2+}$. These $\mathrm{V}_{\mathrm{o}}^{2+}$ states are created when the hole is captured by the $\mathrm{V}_{\mathrm{o}}^{+}$center in a depletion region. The yellow emission $(580 \mathrm{~nm})$ is observed in $\mathrm{ZnO}$ nanorods [18] and un-doped $\mathrm{ZnO}$ thin films [19] which is induced by double ionized oxygen vacancies $\left(\mathrm{V}_{\mathrm{o}}^{2+}\right)$ as well. Therefore, it can be concluded that the broad visible emission stems from combination of two emissions with different oxygen vacancy states. Ning, et al. [20] also found that $\mathrm{V}_{\mathrm{o}}^{+}$and $\mathrm{V}_{\mathrm{o}}^{+}$coexisted in one system, where $\mathrm{V}_{\mathrm{o}}^{2+}$ can trap electrons and become $\mathrm{V}_{\mathrm{o}}^{+}$. The intensity of both peaks related to oxygen vacancies is obviously enhanced with increasing the annealing temperature, meaning an increase in the concentration of oxygen vacancies. The fourth peak around $980 \mathrm{~nm}$ is unique in $\mathrm{Yb}$-doped $\mathrm{ZnO}$, which is attributed to up conversion luminescence of $\mathrm{Yb}^{3+}$ from ${ }^{2} \mathrm{~F}_{5 / 2}$ to ${ }^{2} \mathrm{~F}_{7 / 2}$ [14].

\section{Raman characterization}

Raman spectrum is a powerful tool to identify the extrinsic dopant contamination and the type of defects 
for $\mathrm{ZnO}$ thin films. As for wurtzite structure $\mathrm{ZnO}$ that belongs to the $C_{6 v}^{4}$ space group [21], $\mathrm{A}_{1}$ (LO) $\left(574 \mathrm{~cm}^{-1}\right)$ Raman peak is one of the fundamental phonon modes which is associated with oxygen vacancies, $\mathrm{Zn}$ interstitials, or their complexes [22-24]. As Figure 4 shows, both $\mathrm{A}_{1}$ (LO) phonon mode and second-order $\mathrm{A}_{1}(\mathrm{LO})$ phonon mode $\left(1164 \mathrm{~cm}^{-1}\right)$ exist in $\mathrm{Yb}$-doped $\mathrm{ZnO}$ thin films. Based on the preparation condition and atmosphere of annealing treatment, the $\mathrm{A}_{1}(\mathrm{LO})$ phonon mode is possible to be induced by oxygen vacancies.

\section{X-ray photoelectron spectroscopy}

Figure $5 \mathrm{a}$ shows the typical XPS survey scan for $\mathrm{Zn}_{0.985} \mathrm{Yb}_{0.015} \mathrm{O}$ thin films. Not any impurity element except carbon (C) is detected within the detection limit of XPS. Two Strong $\mathrm{ZnO} 2 \mathrm{p}_{3 / 2}$ peaks and $\mathrm{ZnO} 2 \mathrm{p}_{1 / 2}$ peaks, located at $1022 \mathrm{eV}$ and $1045 \mathrm{eV}$ are observed, which corresponds to $\mathrm{Zn}^{2+}$ in the $\mathrm{ZnO}$ lattice. To further investigate the state of $\mathrm{Zn}$ atom, we try to fit high-resolution $\mathrm{Zn} 2 \mathrm{p}_{3 / 2}$ XPS spectra into two or three peaks, as shown in Figure 5b. However, the fitted peaks cannot match the initial peaks well, indicating the initial peaks are of good symmetry. Therefore, $\mathrm{Zn}$ elements in $\mathrm{Zn}_{0.985} \mathrm{Yb}_{0.015} \mathrm{O}$ thin films only occupy $\mathrm{Zn}^{2+}$ state and bound to oxygen. $\mathrm{Zn}$ vacancies and $\mathrm{Zn}$ interstitials can be neglected. The inset in Figure 5 a shows high-resolution XPS spectra of $\mathrm{Yb}-4 d$ core-level. Each of Yb-4d XPS spectrum consists of four peaks in the range of $180 \mathrm{eV} \sim 210 \mathrm{eV}$. These peaks are ascribed to $\mathrm{Yb}^{3+}$, thus the existence of $\mathrm{Yb}$ cluster and $\mathrm{Yb}^{2+}$ can be excluded $[25,26]$. High-resolution XPS spectra of $\mathrm{O}-1$ s core-level, as shown in Figure $5 \mathrm{c}$, are recorded to investigate the state of $1 \mathrm{~s}$ electrons of oxygen. Contrary to other peaks, these peaks exhibit clear asymmetry, which is an indication that different $\mathrm{O}$ states coexist in $\mathrm{Zn}_{0.985} \mathrm{Yb}_{0.015} \mathrm{O}$ thin films. All O-1s core-level XPS spectra can be fitted into two different peaks located at $530.0 \mathrm{eV}$ and $531.5 \mathrm{eV}$, as shown in Figure 5d. The former peak $\left(\mathrm{O}_{\mathrm{a}}\right)$ is originated from $\mathrm{O}^{2-}$ ions in the normal lattice sites surrounded by $\mathrm{Zn}^{2+}$ and $\mathrm{Yb}^{3+}$. However, explanation for the latter peak $\left(\mathrm{O}_{\mathrm{b}}\right)$ is controversial. Some researchers claimed that the peak around $532.0 \mathrm{eV}$ originated from near-surface oxygen or absorbed oxygen, while other researchers believed this peak came from $\mathrm{O}^{2-}$ ions in the oxygen-deficient regions [27,28]. In this experiment, both the film preparation process and annealing treatment are performed at oxygen-deficient environment. Thus, the $\mathrm{O}_{\mathrm{b}}$ peak is probably attributed to latter explanation. Besides, it is found that the position of $\mathrm{O} 1 \mathrm{~s}$ peaks for annealed samples shifts to higher binding energy. There are researchers $[29,30]$ reporting that the existence of oxygen vacancies can cause the shift to higher binding energy. Therefore, more oxygen vacancies are formed during the annealing process. Based on the Raman, PL and XPS results, it can be concluded that the main defect in our $\mathrm{Yb}$-doped $\mathrm{ZnO}$ thin films is oxygen vacancies.

\section{Discussion}

Based on above XRD, Raman, XPS, PL and magne-
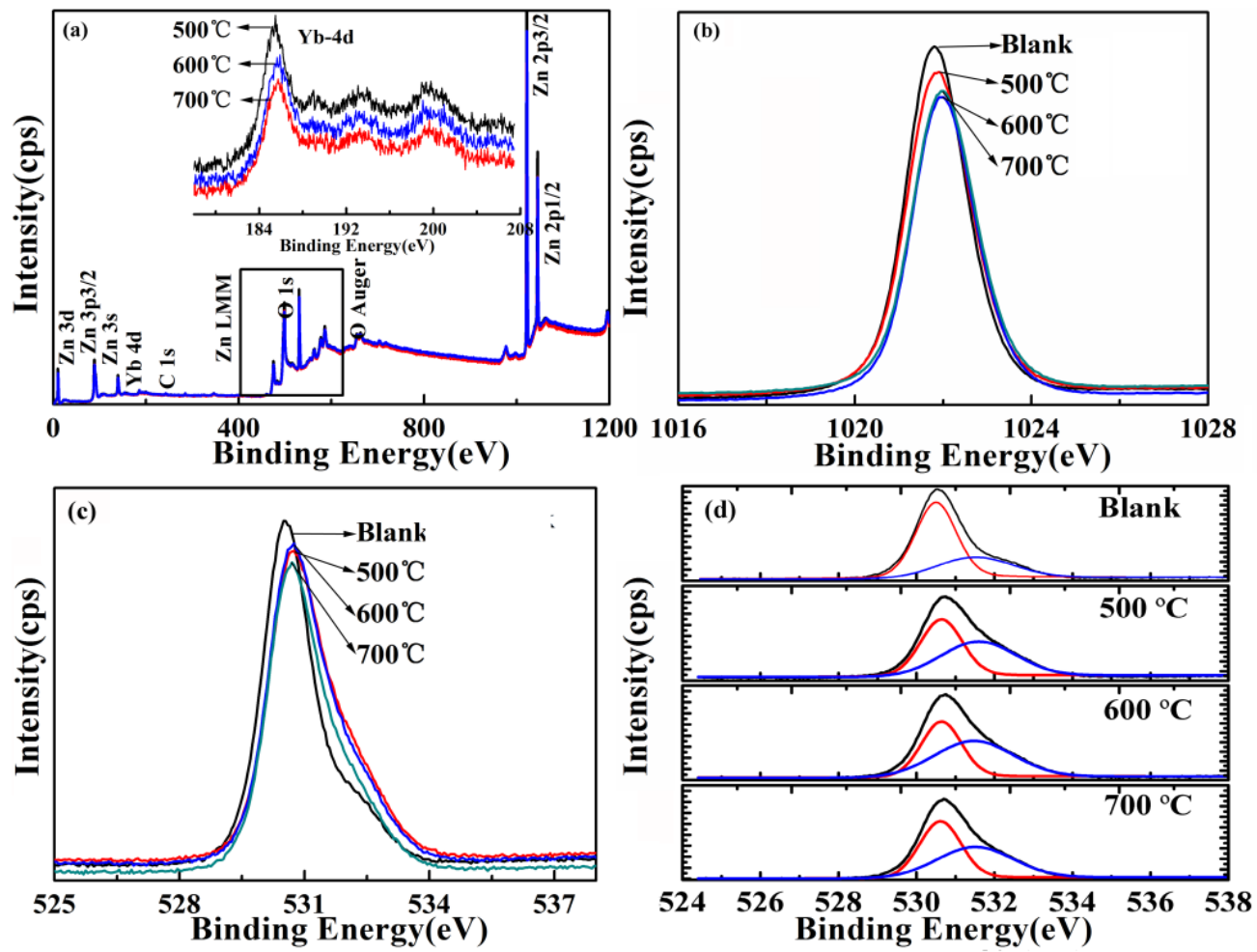

Figure 5: a) XPS spectra; b) Zn-2 $p_{3 / 2}$ high-resolution XPS spectrum; c) O-1s high-resolution XPS spectrum; d) $\mathrm{O}_{a}$ and $\mathrm{O}_{b}$ for $\mathrm{Zn}_{0.985} \mathrm{Yb}_{0.015} \mathrm{O}$ thin films annealed at $500^{\circ} \mathrm{C}, 600^{\circ} \mathrm{C}$ and $700^{\circ} \mathrm{C}$ in $\mathrm{H}_{2}$ atmosphere for $1 \mathrm{~h}$. 


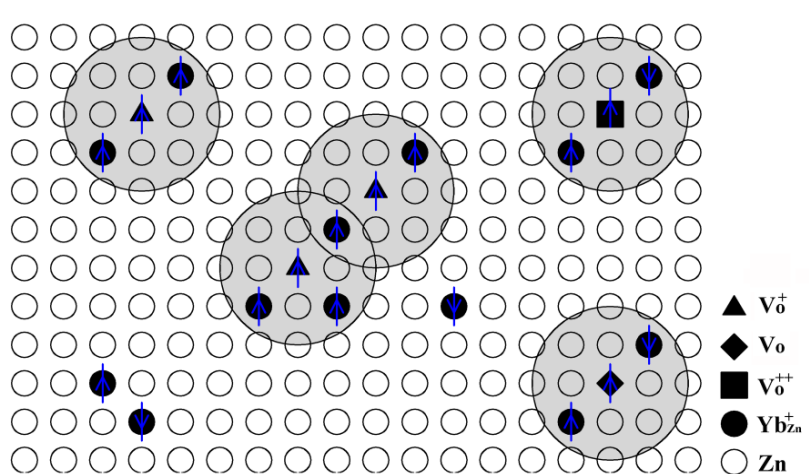

Figure 6: The schematic illustration of ferromagnetism mechanism in Yb-doped $\mathrm{ZnO}$ system.

tization results, it can be concluded that the bridge between annealing temperature and magnetism is oxygen vacancy. Oxygen vacancies can carry different amount of charge, such as $\mathrm{V}_{\mathrm{o}}^{2+}, \mathrm{V}_{\mathrm{o}}^{+}$and $\mathrm{V}_{\mathrm{O}}$. Among them, only $\mathrm{V}_{\mathrm{o}}^{+}$has net magnetic moments and can contribute to the ferromagnetism [20]. BMP model is a proposed theory to explain the origin of room-temperature ferromagnetism for defect-rich material. This is also favors Yb-doped $\mathrm{ZnO}$ system. In this system, $\mathrm{V}_{\mathrm{o}}^{+}$can capture an electron from the conduction band, turning into $\mathrm{V}_{\mathrm{o}}^{+}$. The electron trapped locally around the oxygen vacancies 5678 occupies an orbit overlapping with $4 f$-shell electrons of $\mathrm{Yb}_{\mathrm{Zn}}$ neighbors, because of quantum effect, the orientation of magnetic moments of oxygen vacancies is coincident with that of $\mathrm{Yb}$ atom, forming BMPs. The formed BMPs randomly associate with oxygen vacancies overlap, leading to long-range ferromagnetic ordering, as Figure 6 illustrates.

\section{Conclusion}

In conclusion, $\mathrm{Zn}_{0.985} \mathrm{Yb}_{0.015} \mathrm{O}$ thin films have been prepared by using inductively coupled plasma enhanced physical vapor deposition method and then annealed in hydrogen atmosphere at $500{ }^{\circ} \mathrm{C}, 600{ }^{\circ} \mathrm{C}$ and $700{ }^{\circ} \mathrm{C}$ for $1 \mathrm{~h}$. We perform an in-depth study on the influence of annealing temperature on structural, optical and magnetic properties. The crystallization quality of $\mathrm{Zn}_{0.985} \mathrm{Yb}_{0.015} \mathrm{O}$ thin films is obviously improved after annealing process. The amount of oxygen vacancies rises with increasing the annealing temperature. Single and double ionized oxygen vacancies coexist in $\mathrm{Zn}_{0.985} \mathrm{Yb}_{0.015} \mathrm{O}$ thin films, but only single ionized oxygen vacancies make contribution to ferromagnetism. BMP model is well used to explain the ferromagnetic mechanism of $\mathrm{Yb}$-doped $\mathrm{ZnO}$ thin films.

\section{Acknowledgments}

This work is sponsored by the National Key $R \& D$ Program of China (Grant Nos. 2016YFB0400401 \& 2017YFB0405700) and Young Scientists Fund of the National Natural Science Foundation of China (Grant no. 51602331).

\section{References}

1. Azam A, Ahmed F, Habib S, Zishan H Khan, Numan A Salah (2013) Fabrication of Co-doped $\mathrm{ZnO}$ nanorods for spintronic devices. Metals and Materials International 4: 845-850.

2. Gupta S, Fenwick WE, Melton A, Zaidi T, Yu H, et al. (2008) MOVPE growth of transition-metal-doped $\mathrm{GaN}$ and $\mathrm{ZnO}$ for spintronic applications. Journal of Crystal Growth 310: 5032-5038.

3. Dietl T, Ohno H, Matsukura F, Cibert J, Ferrand D (2000) Zener model description of ferromagnetism in zinc-blende magnetic semiconductors. Science 287: 1019-1022.

4. Choi E-A, Lee W-J, Chang KJ (2010) Enhanced electron-mediated ferromagnetism in Co-doped $\mathrm{ZnO}$ nanowires. Journal of Applied Physics 108: 023904.

5. Singh AP, Park BG, Lee I-J, Lee KJ, Jung MW, et al. (2013) Hole mediated ferromagnetism in Cu-doped $\mathrm{ZnO}$ thin films on $\mathrm{GaAs}$ substrate. Journal of Magnetism and Magnetic Materials 328: 58-61.

6. Liu XJ, Song C, Zeng F, Pan F, He B, et al. (2008) Strain-induced ferromagnetism enhancement in $\mathrm{Co:ZnO}$ films. Journal of Applied Physics 103: 093911.

7. Coey JMD, Venkatesan M, Fitzgerald CB (2005) Donor impurity band exchange in dilute ferromagnetic oxides. Nat Mater 4: 173-179.

8. Gu H, Zhang W, Xu Y, Yan M (2012) Effect of oxygen deficiency on room temperature ferromagnetism in Co doped ZnO. Applied Physics Letters 100: 202401.

9. Gu H, Jiang Y, Xu Y, Yan M (2011) Evidence of the defect-induced ferromagnetism in $\mathrm{Na}$ and $\mathrm{Co}$ codoped $\mathrm{ZnO}$. Applied Physics Letters 98: 012502.

10. Chen H-M, Liu X-C, Zhuo S-Y, Xiong Z, Zhou RW, et al. (2014) Zinc vacancy and erbium cluster jointly promote ferromagnetism in erbium-doped $\mathrm{ZnO}$ thin film. AIP Advances 24: 047121.

11. Yi JB, Lim CC, Xing GZ, Fan HM, Van LH, et al. (2010) Ferromagnetism in dilute magnetic semiconductors through defect engineering: Li-Doped ZnO. Phys Rev Lett 104: 137201.

12. Shi T, Xiao Z, Yin Z, Li X, Wang Y, et al. (2010) The role of $\mathrm{Zn}$ interstitials in cobalt-doped $\mathrm{ZnO}$ diluted magnetic semiconductors. Applied Physics Letters 96: 211905.

13. You H, Yang J, Zhu JY, Xu WF, Tang XD (2012) Oxygen interstitials enhanced room temperature ferromagnetism in undoped zinc oxide. Applied Surface Science 258: 4455-4459.

14. Li F, Liu X-C, Zhou R-W, Chen HM, Zhou SY, et al. (2014) Strong correlation between oxygen vacancy and ferromagnetism in $\mathrm{Yb}$-doped $\mathrm{ZnO}$ thin films. Journal of Applied Physics 116: 243910.

15. Sanon G, Rup R, Mansingh A (1990) Growth and characterization of tin oxide films prepared by chemical vapour deposition. Thin Solid Films 190: 287-301.

16. Chen Z, Li XX, Du G, Chen N, Suen AYM (2011) A sol-gel method for preparing $\mathrm{ZnO}$ quantum dots with strong blue emission. Journal of Luminescence 131: 2072-2077.

17. Jana A, Sujatha Devi P, Mitra A, Bandyopadhyay NR (2013) Synthesis of blue emitting $\mathrm{ZnO}$ nanorods exhibiting room temperature ferromagnetism. Materials Chemistry and Physics 139: 431-436. 
18. Panigrahy B, Aslam M, Misra DS, Ghosh M, Bahadur D (2010) Defect-related emissions and magnetization properties of zno nanorods. Advanced Functional Materials 20: 1161-1165.

19. Zhan P, Wang WP, Liu C, Hu Y, Li Z, et al. (2012) Oxygen vacancy-induced ferromagnetism in un-doped $\mathrm{ZnO}$ thin films. Journal of Applied Physics 111

20. Ning S, Zhan P, Wang W-P, Li Z-C, Zhang Z-J (2014) Defect characterization and magnetic properties in un-doped $\mathrm{ZnO}$ thin film annealed in a strong magnetic field. Chinese Physics B 23.

21. Huang Y, Liu M, Li Z, Zeng Y, Liu S (2003) Raman spectroscopy study of $\mathrm{ZnO}$-based ceramic films fabricated by novel sol-gel process. Materials Science and Engineering: B 97: 111-116.

22. Wang JB, Huang GJ, Zhong XL, Sun LZ, Zhou YC (2006) Raman scattering and high temperature ferromagnetism of Mn-doped $\mathrm{ZnO}$ nanoparticles. Applied Physics Letters 88: 252502.

23. Du CL, Gu ZB, Lu MH, Wang J, Zhang ST (2006) Raman spectroscopy of (Mn, Co)-codoped ZnO films. Journal of Applied Physics 99: 123515.

24. Wang XB, Song C, Geng KW, Zeng F, Pan F (2007) Photoluminescence and Raman scattering of $\mathrm{Cu}$-doped $\mathrm{ZnO}$ films prepared by magnetron sputtering. Applied Surface Science 253: 6905-6909.

25. Wang HM, Simmonds MC, Rodenburg JM (2003) Manufacturing of $\mathrm{YbAG}$ coatings and crystallisation of the pure and Li2O-doped $\mathrm{Yb} 2 \mathrm{O} 3-\mathrm{Al} 2 \mathrm{O} 3$ system by a modified solgel method. Materials Chemistry and Physics 77: 802-807.

26. Ohno Y (2008) XPS studies of the intermediate valence state of $\mathrm{Yb}$ in $(\mathrm{YbS}) 1.25 \mathrm{CrS} 2$. Journal of Electron Spectroscopy and Related Phenomena 165: 1-4.

27. Hsieh PT, Chen YC, Kao KS, Wang CM (2008) Luminescence mechanism of $\mathrm{ZnO}$ thin film investigated by XPS measurement. Applied Physics A 90: 317-321.

28. Lu YF, Ni HQ, Mai ZH, Ren ZM (2000) The effects of thermal annealing on $\mathrm{ZnO}$ thin films grown by pulsed laser deposition. Journal of Applied Physics 88: 498-502.

29. Colon G, Hidalgo MC, Munuera G, Ferino I, Cutrufello MG, et al. (2006) Structural and surface approach to the enhanced photocatalytic activity of sulfated $\mathrm{TiO} 2$ photocatalyst. Applied Catalysis B: Environmental 63: 45-59.

30. Hughes AE, Gorman JD, Patterson PJK, Carter R (1996) Unusual peak shifts in the core levels of $\mathrm{CeO} 2$ films deposited on $\mathrm{Si}(100)$. Surface and Interface Analysis 24: 634640 